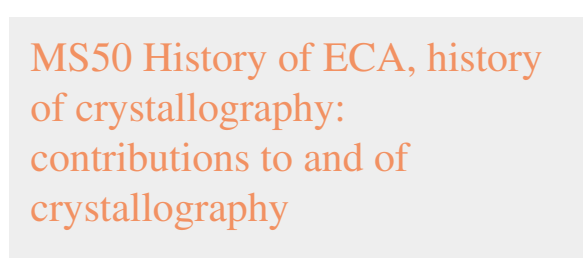

Chairs: Menahem Kaftory, Peter Paufler pioneering chemists at the Universities of Bern (topochemistry by V. Kohlschütter and basic salts of divalent metals by W. Feitknecht) and Geneva (K.H. Meyer, fibers and polymers). From the 1970s onward, Swiss crystallography has developed similarly to elsewhere.

Keywords: Kappeler, Laue, Bragg, Scherrer, Niggli, Laves, Nowacki

\section{MS50-01 History of crystallography in Switzerland}

Dieter Schwarzenbach ${ }^{1}$

1. École Polytechnique Fédérale, SB-DO, Le Cubotron, CH-1015 Lausanne

email: dieter.schwarzenbach@epfl.ch

Laue's experiment in 1912 of the diffraction of X-rays by crystals led to one of the most influential revolutions in the history of science: the determination of crystal structures, the first structures being those of $\mathrm{NaCl}$ by W.L. Bragg, and diamond by W.L. Bragg and W.H. Bragg in 1913. The visualisation of matter with a sort of microscope possessing atomic resolution revolutionized chemistry and solid-sate physics. By the early 1920s, the physics of X-ray diffraction was worked out, including atomic form and temperature factors, dynamical diffraction, application of space group symmetry, and the determination of simple structures. By the 1970s, the technical developments of X-ray tubes, cameras, detectors, diffractometers, computers and powerful software have enabled the art of structure determination to become a tool for chemical analysis. Since then, ever increasing efficiency of diffraction experiments and structure determination has resulted in service crystallography and an ever increasing demand for diffraction methods. Swiss contributions may be found in the early history of crystallography. Moritz Anton Kappeler, town physician of Lucerne, published an influential treatise on crystals in 1723. Debye and Scherrer moved to Zürich soon after their invention of powder diffraction. The most noteworthy Swiss contribution to early crystallography is certainly Paul Niggli's influential "Zürich School of Crystallography" in the Earth Sciences of the ETH and the University from 1920 to the retirement of Niggli's successor Fritz Laves in 1976. Its pioneering work was in the fields of space group symmetry (the precursor of the International Tables), geometrical crystallography (domains of influence of symmetry elements, homogeneous space partitions) and crystal chemistry, rather than in structure determination. The tradition of the "Zürich School", but also including structure determination (e.g. sulfo salts), was continued by Niggli's student Werner Nowacki at the University of Bern. Chemical Crystallography and structures of organic compounds was imported from the UK when J.D. Dunitz arrived at ETH Zürich in 1957. However, diffraction methods were applied to chemical problems early on by 